\title{
A case of Kallmann syndrome
}

\author{
Maria Luisa Cecilia R Arkoncel, ${ }^{1}$ Francis Raymond P Arkoncel, ${ }^{2}$ Frances Lina Lantion-Ang ${ }^{1}$ \\ ${ }^{1}$ Section of Endocrinology, Diabetes and Metabolism, Department of Medicine, Philippine General Hospital, University of the Philippines Manila, Manila, Philippines;
} ${ }^{2}$ Division of Urology, Department of Surgery, Philippine General Hospital, University of the Philippines Manila, Manila, Philippines

Correspondence to Dr Maria Luisa Cecilia Rivera-Arkoncel, luisa0477@yahoo.com

\begin{abstract}
Summary
Kallmann syndrome (KS), a rare genetic disorder, refers to the association between hypogonadotropic hypogonadism and anosmia or hyposmia due to abnormal migration of olfactory axons and gonadotropin-releasing hormone producing neurons.

The authors report a case of a 26-year-old Filipino male who presented with eunuchoid body proportion, absence of facial and axillary hair and sparse pubic hair, micropenis and bilaterally descended prepubertal testes. Associated findings were hyposmia, high pitched voice, absence of puncta and smooth philtrum. Hormonal assay showed hypogonadotropic hypogonadism. He has normal male karyotype. Ultrasonography revealed no renal abnormalities. MRI of the brain showed hypoplastic left olfactory bulb and aplastic right olfactory bulb. These findings are characteristic of KS. Androgen replacement with testosterone was started to induce virilisation. Our patient is now on regular follow-up to monitor response to treatment.
\end{abstract}

\section{BACKGROUND}

Kallmann syndrome (KS), the association of hypogonadotropic hypogonadism and anosmia, was described by Maestre de San Juan in 1856 and characterised as a hereditary condition by Franz Josef Kallmann in $1944 .{ }^{1}$ It is now designated as olfactogenital dysplasia to emphasise the association between agenesis of the olfactory bulbs and hypogonadism. ${ }^{2}$ There are alterations of several specific genes that prevent the migration of the gonadotropin-releasing hormone $(\mathrm{GnRH})$ cells and the olfactory nerve from their common origin in the olfactory placode early in fetal development. ${ }^{3}$ It is a rare genetic disorder with a prevalence of 1 in 10000 to 1 in 60000 with a male to female ratio of 5:1. ${ }^{4}$

\section{CASE PRESENTATION}

A 26-year-old Filipino male presented at the Philippine General Hospital outpatient clinic because of the absence of pubertal development. He was born full term via normal spontaneous delivery to a 26-year-old mother. He has no siblings. He was circumcised at birth. Micropenis was observed but no further consultation was sought. He had normal developmental milestones and intelligence was at par with age. At 11 years of age, he was seen at Ophthalmology clinic for frequent lacrimation. He was diagnosed with bilateral congenital absence of upper and lower puncta. He was advised further evaluation and possible corrective surgery, however, he was lost to follow-up. At age 15 he had psychiatric counselling for a conduct disorder from a disruptive behaviour after friends kept on teasing him for 'looking like a girl'. It was at this time that he noted hyposmia. He had no history of seizures, blurring of vision, colour blindness, hearing loss and movement disorders. At present, he is a second year college student. Family history is unremarkable on the maternal side. No medical information can be obtained on the paternal side.

On physical examination, his weight was $52 \mathrm{~kg}$, height was $170 \mathrm{~cm}$, arm span was $176 \mathrm{~cm}$, crown to pubis was
$74 \mathrm{~cm}$, pubis to heel was $96 \mathrm{~cm}$ with a ratio of $0.77 \mathrm{com}-$ patible with eunuchoid stature.

He has high pitched voice, absent upper and lower puncta bilaterally, smooth philtrum and thin upper lip (figure 1). He showed absence of hair over face, axillae and legs. He has sparse pubic hair (Tanner stage 2), bilateral descended prepubertal testes measuring $1 \mathrm{ml}$ using the orchidometer and microphallus, with penile length of 2.0 $\mathrm{cm}$ (figure 2). There were no other abnormalities on systemic examination. Neurologic examination was essentially normal except for decreased sense of smell.

\section{INVESTIGATIONS}

Abdominal ultrasonography revealed normal liver, gallbladder, pancreas, spleen, kidneys and urinary bladder. Both testes are small in size and volume $(<4 \mathrm{cc})$ on scrotal ultrasound; the right testis measures $1.8 \times 1.3 \times 0.8 \mathrm{~cm}$ and the left testis measures $1.8 \times 1.2 \times 0.8 \mathrm{~cm}$.

Karyotyping was normal male (46XY).

Hormonal assay results included serum follicle-stimulating hormone (FSH), luteinising hormone ( $\mathrm{LH})$ and testosterone which revealed hypogonadotropic hypogonadism (table 1).

Radioisotope Laboratory Philippine General Hospital Imaging MRI of the brain showed normal pituitary gland, hypoplastic left olfactory bulb and aplastic right olfactory bulb (figures 3-5).

\section{TREATMENT}

He was started on androgen replacement with testosterone injections to induce virilisation which was his immediate goal.

\section{OUTCOME AND FOLLOW-UP}

$\mathrm{He}$ is now on regular follow-up to monitor response to treatment. During his latest evaluation, he was observed 


\section{BMJ Case Reports}

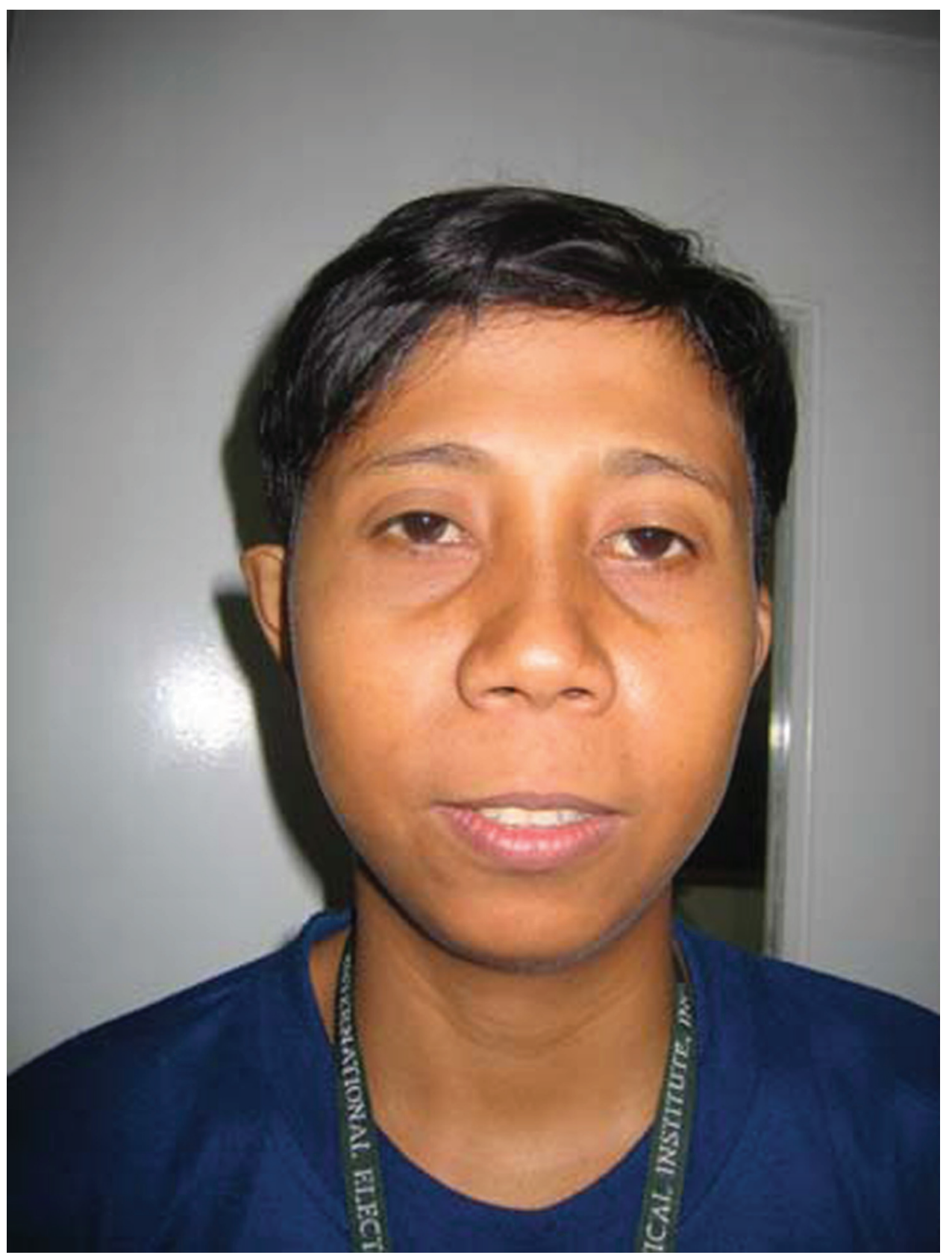

Figure 1 The smooth philtrum and thin upper lip.

to have deep voice and increased penile length and appearance of coarse pubic hair after 7 months (figure 6). Serum testosterone was within normal limits.

\section{DISCUSSION}

$\mathrm{KS}$ is characterised by hypogonadotropic hypogonadism and hyposmia or anosmia. It results from the impairment of $\mathrm{GnRH}$ and olfactory neurons to migrate from the olfactory placode to the hypothalamus. ${ }^{5}$ It is a genetically heterogenous disorder that may be inherited in an $\mathrm{X}$-linked, autosomal dominant or autosomal recessive pattern. The most prevalent is an X-linked form that maps to the KAL1 gene which encodes for a neuron adhesion molecule thought to be responsible for guiding migration of LH-releasing hormones-secreting neurons to the medial basal hypothalamus. Complete or partial anosmia is a consistent finding in these patients. Cryptorchidism and gynecomastia are common and micropenis occurs in approximately $50 \%$ of affected males. The primary hormonal defect is a failure of $\mathrm{GnRH}$ secretion by the hypothalamus, leading to secondary testicular failure. ${ }^{6}$

A delay in pubertal development is the hallmark of the syndrome. This is the most common cause for affected patients to seek medical evaluation. ${ }^{6}$ Delayed puberty refers to the absence of pubertal onset by the expected age or once puberty has commenced, failure of appropriate progression. Boys are considered to have delayed puberty if at the age of 14 , they have not undergone pubertal changes. ${ }^{2}$

Our patient presented with delayed puberty, characterised by high pitched voice, absence of facial and 


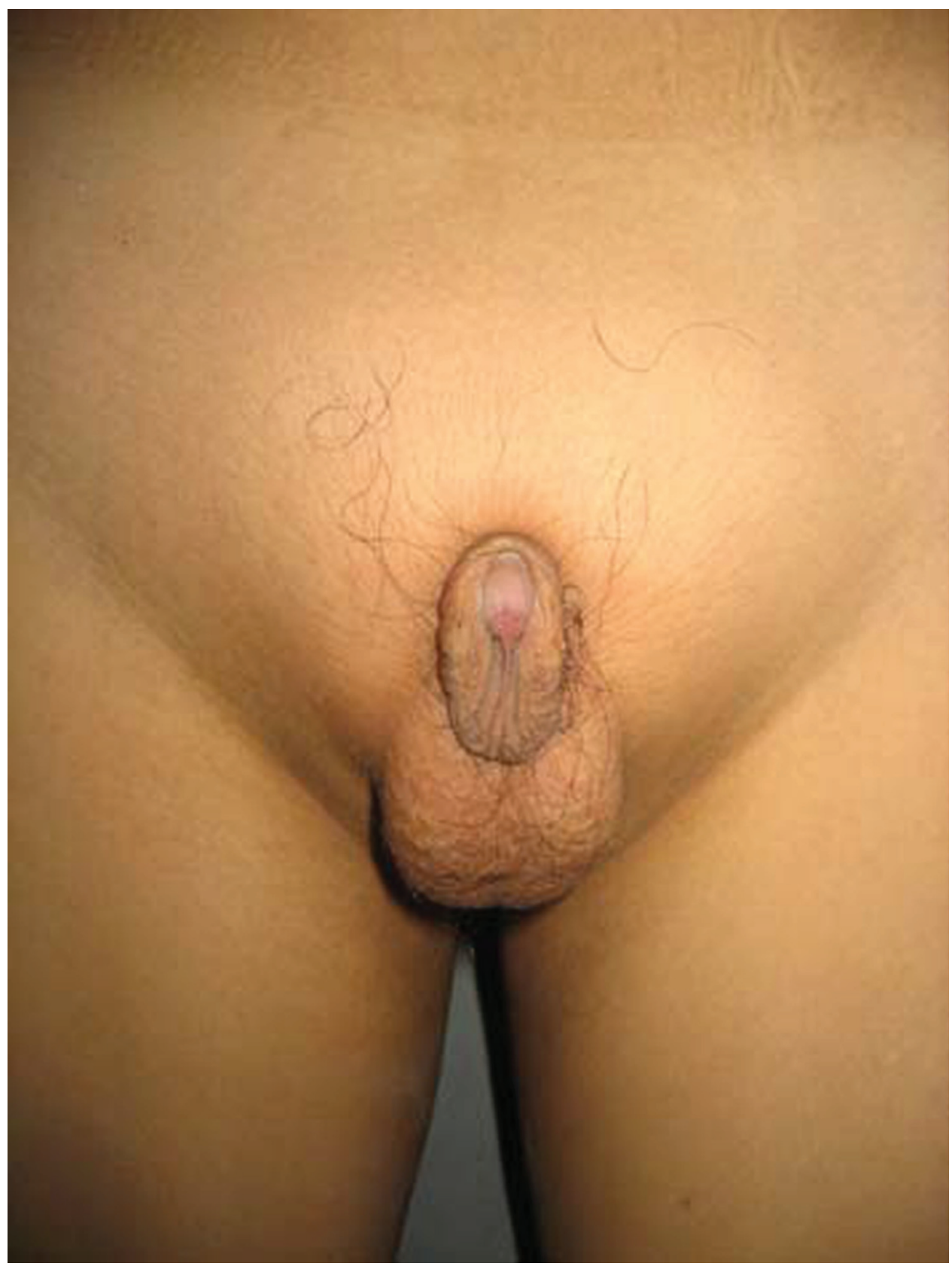

Figure 2 Micropenis, bilaterally descended prepubertal testes and sparse pubic hair.

Table 1 Results of serum FSH, LH and testosterone

\begin{tabular}{lll}
\hline Hormones & Patient values & Normal values \\
\hline Serum FSH & $0.8 \mathrm{mlU} / \mathrm{ml}$ & $1-10.5 \mathrm{mlU} / \mathrm{ml}$ \\
Serum LH & $0.3 \mathrm{mlU} / \mathrm{ml}$ & $1.9-9.4 \mathrm{mlU} / \mathrm{ml}$ \\
Serum testosterone & $1.4 \mathrm{nmol} / \mathrm{l}$ & $9-38 \mathrm{nmol} / \mathrm{l}$ \\
\hline
\end{tabular}

FSH, follicle-stimulating hormone; $\mathrm{LH}$, luteinising hormone.

axillary hair and sparse pubic hair, micropenis and bilateral small testes. Hormonal evaluation showed low FSH, low LH and low testosterone levels. A diverse group of disorders with varied pathophysiology comprise hypogonadotropic hypogonadism or hypothalamic pituitary hypogonadism. Examples include an isolated abnormality in hypothalamic $\mathrm{GnRH}$, isolated abnormality in pituitary gonadotropins (LH, FSH) and conditions in which both hypothalamic and pituitary dysfunction are present. Differential diagnosis will include KS, GnRH receptor mutation, GPR54 mutation, DAX-1 mutation and hypopituitarism. ${ }^{2}$

A shared trait among these patients is a characteristic body habitus. ${ }^{2}$ As a result of a delay in androgen dependent closure of the epiphysial plates, the length of the arms and legs may be greater than that of the trunk. ${ }^{6}$ Our patient has an arm span of $6 \mathrm{~cm}$ more than his height and an upper to lower segment ratio of 0.77 , confirming the presence of 'eunuchoid' stature (arm span $>5 \mathrm{~cm}$ than height, upper to lower segment ratio $<0.9){ }^{2}$

The diagnosis of $\mathrm{KS}$ in this case is straightforward because of the hypogonadotropic hypogonadism in association with hyposmia and documented radiologic findings in MRI. 


\section{BMJ Case Reports}

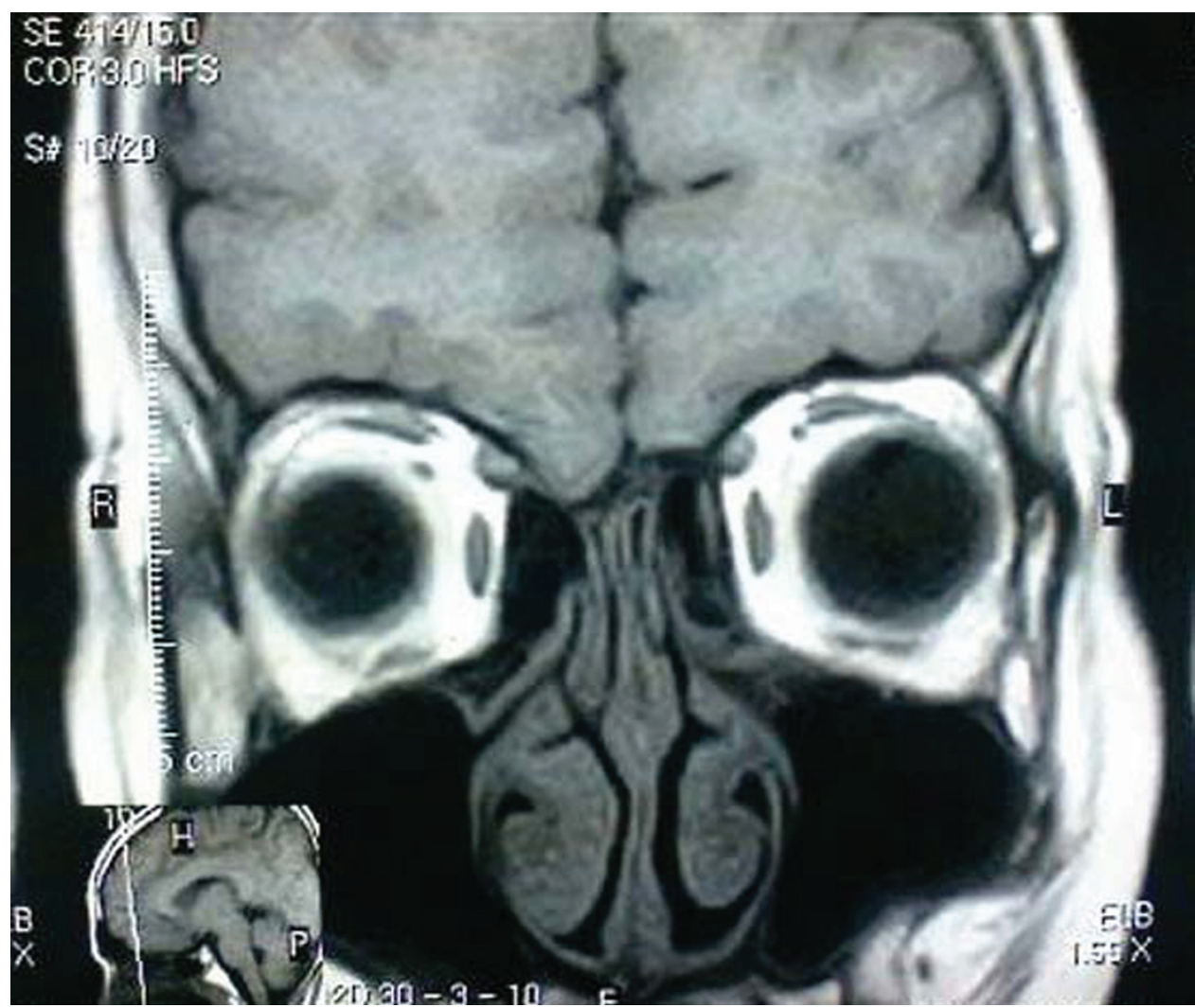

Figure 3 Coronal T1 weighted image demonstrating hypoplastic left and aplastic right olfactory bulb.

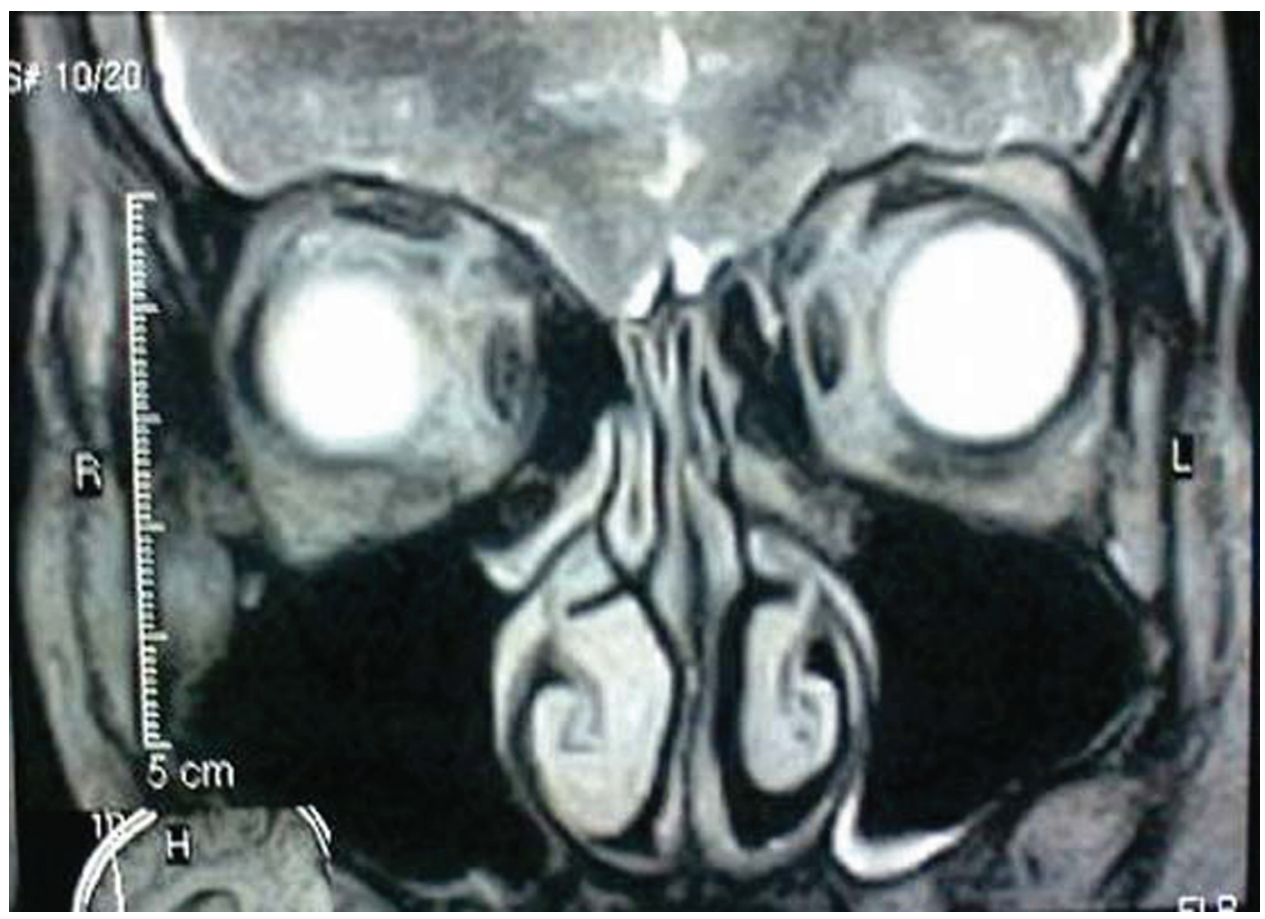

Figure 4 Coronal T2 weighted image demonstrating hypoplastic left and aplastic right olfactory bulb.

Morphological abnormalities of olfactory apparatus in KS are best evaluated with MRI. Madan et al reported MRI findings of five male patients with clinical findings suggestive of KS syndrome. All patients had hypogonadotropic hypogonadism and anosmia. Abnormalities of olfactory sulci and bulbs were noted in all five patients. All patients had absent olfactory bulbs. ${ }^{7}$ Cranial MRI in our case revealed hypoplastic left olfactory bulb and aplastic right olfactory bulb. The pituitary gland is normal. 


\section{BMJ Case Reports}

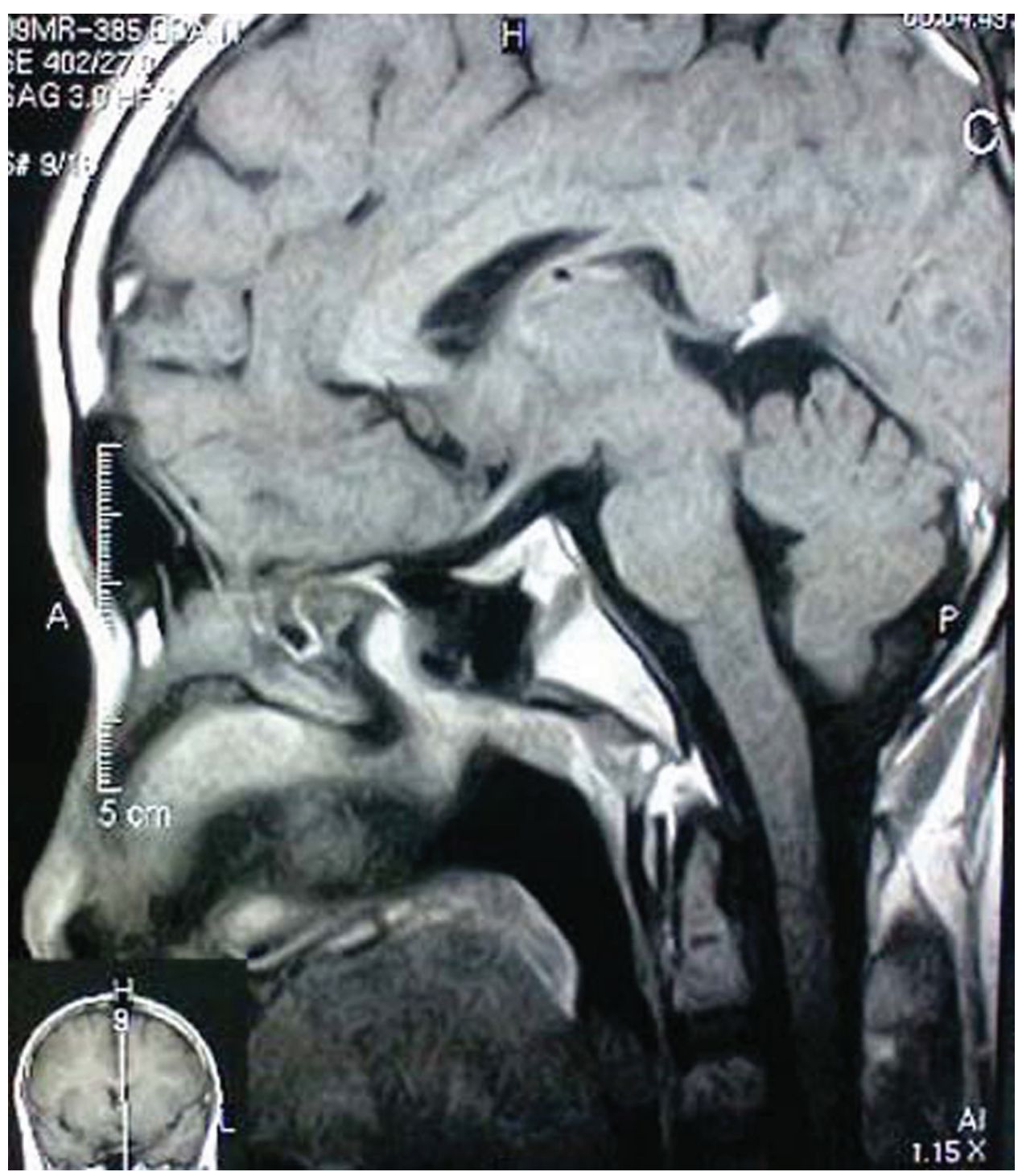

Figure 5 Sagittal T1 weighted image showing hypoplastic left olfactory bulb.

Clinical diagnosis of KS in adults is fairly clear-cut, depending on the co-existence of anosmia with subnormal levels of gonadal steroid and gonadotropins. However, the diagnosis may be difficult to establish in patients of prepubertal age who may require genetic testing and MRI. ${ }^{7}$ In these group of patients, MRI will aid in the diagnosis of KS by demonstration of characteristic abnormalities in olfactory sulci and tracts.

Other multiple congenital anomalies such as craniofacial asymmetry, cleft palate, harelip, colour blindness, congenital deafness and renal anomalies may be associated with this syndrome. ${ }^{6}$

Our patient presented with congenital absence of both puncta and smooth philtrum which are not commonly seen in KS. Field theory model of facial development explains the developmental anatomy of the contents of the nasal capsule. The presence of paired A fields originating from prechordal mesendoderm associated with nasal and optic placodes explain the internal structure of nose and that of oronasal midline. It also shares common genetic coding with prosomeres of the forebrain. The lacrimals, orbits ethmoids, turbinates, premaxillae, vomerine bones and cartilages of the nose are formed from fusion of these fields. KS is one of the clinical models that demonstrate the effects of anatomic disturbances within the A fields. ${ }^{8}$

Hunter et al described a case of mother and son who had identical facies (square forehead, telecanthus, flat nasal bridge, thin upper lip, smooth philtrum) and marked brachytelephalangy. The son had KS. ${ }^{9}$ Our patient, apart from the absence of puncta and smooth philtrum, has no other associated defects. He has no cleft palate, colour blindness, abnormal eye movements, sensorineural hearing loss, synkinesia and renal abnormalities. Referral to ophthalmology to address the congenital absence of upper and lower puncta was made. Corrective surgery is being contemplated pending full evaluation.

Reviewing the local literature, we only found one case report of KS in two brothers. It was the first case report on the syndrome locally. Two cases of hypogonadotropic hypogonadism with anosmia were seen at the Philippine General Hospital in 1991. Both had eunuchoid body proportion, absence of secondary sexual characteristics, bilateral 


\section{BMJ Case Reports}

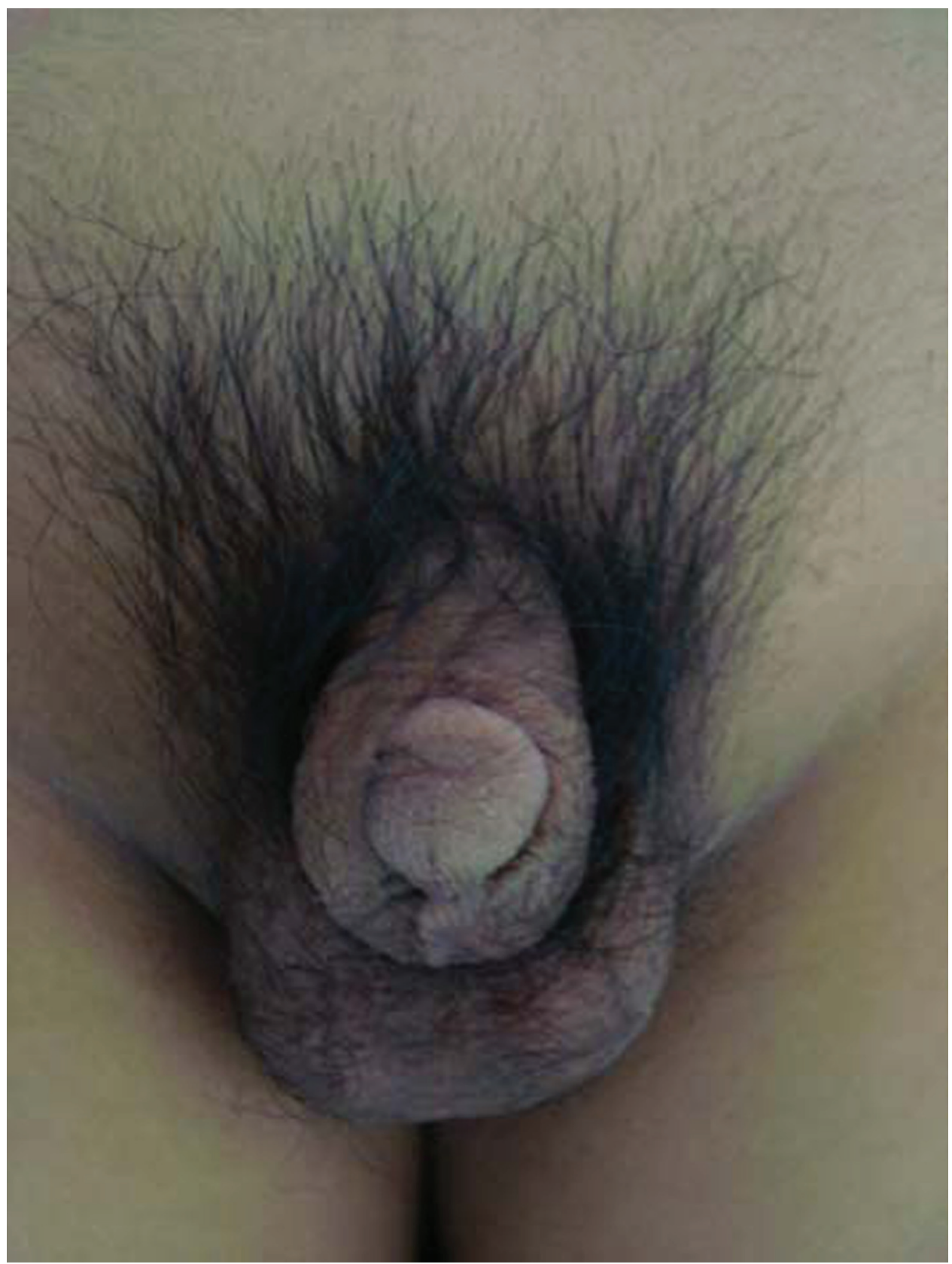

Figure 6 An increased penile length and appearance of coarse pubic hair after two doses of intramuscular testosterone injections.

cryptorchidism and failure to ejaculate. In contrast to our case, both had no facial anomalies and presented with bilateral cryptorchidism. A cone view of the sella in both patients showed normal result. At the time of the report, both patients were still to undergo further evaluation. ${ }^{10}$ To our knowledge, this is the second local case report on the syndrome, and the first local case report to describe the radiologic aspect of the syndrome.

Treatment of patients with KS should be individualised. Androgen deficiency is treated with testosterone to effect virilisation. This is the treatment of choice whenever fertility is not currently wanted. Human chorionic gonadotrophin (hCG) treatment is initiated when fertility is desired. Treatment with testosterone for many years does not preclude a favourable response to hCG. ${ }^{2}$
Our patient did not present with cryptorchidism. In a study done by Abujbara et al ${ }^{11}$ in 2004, cryptorchidism or a history of cryptorchidism was present in $73 \%$ of patients (19/26). In KS with cryptorchidism, chorionic gonadotropin therapy improved the cryptorchid state without the need of surgery. ${ }^{12}$ This should be kept in mind whenever we see these patients. In such cases, medical therapy may benefit and surgery may not always be the first treatment to offer. Detailed history taking and meticulous physical examination are very important to arrive at an early and correct diagnosis. This will translate to adequate medical treatment and may prevent unnecessary surgical intervention for cryptorchidism.

Since hyposmia in KS is due to the pathology in the olfactory bulb, no cure is available. Patient reassurance and 
education were given. Hazards were also emphasised. He was warned that this will render him unable to detect certain hazards and lifestyle adjustments may be necessary. He was advised to pay attention to the expiration date on food to avoid eating items which are spoiled and also to possibly install smoke detectors at home to minimise risk in the home environment.

In summary, we have a case of $\mathrm{KS}$, who early in life presented with micropenis but unfortunately was not further evaluated. He subsequently presented with eunuchoid body proportion, high pitched voice, absence of facial and axillary hair and sparse pubic hair, micropenis and bilaterally descended prepubertal testes. Associated findings were hyposmia and facial anomalies namely congenital absence of puncta and smooth philtrum. Hormonal evaluation was consistent with hypogonadotropic hypogonadism. Cranial MRI showed aplastic right olfactory bulb and hypoplastic left olfactory bulb.

\section{Learning points}

-We highlighted the clinical, hormonal and radiologic aspects of this case.

- KS presents with signs and symptoms from multiple organ systems, which, if not taken together, could lead to a missed or late diagnosis.

- These findings should be recognised in patients presenting in our clinics to ensure that the diagnosis of KS is not overlooked and adequate treatment is initiated.

- Treatment of KS includes hormone replacement therapy, which elicits virilisation, promotes fertility and may prevent unnecessary surgery for some patients who present with cryptorchidism.
Competing interests None.

Patient consent Obtained.

\section{REFERENCES}

1. Ribeiro RS, Abucham J. Kallmann syndrome: a historical (corrected) clinical and molecular review. Arq Bras Endocrinol Metabol 2008;52:8-17.

2. Degroot L, Jameson JL. Endocrinology. Fifth edition. Philadelphia, PA: Elsevier Saunders 2006:2847-9, 3162-7.

3. De Bellis A, Sinisi AA, Conte M, et al. Antipituitary antibodies against gonadotropin-secreting cells in adult male patients with apparently idiopathic hypogonadotropic hypogonadism. J Clin Endocrinol Metab 2007;92:604-7.

4. Kulkarni ML, Balaji MD, Kulkarni AM, et al. Kallmann's syndrome. Indian J Pediatr 2007:74:1113-5.

5. Bhagavath B, Layman LC. The genetics of hypogonadotropic hypogonadism. Semin Reprod Med 2007;25:272-86.

6. Wein AJ. (ed) Campbell-Walsh Urology. Ninth edition. Philadelphia, PA: Elsevier Saunders 2007:635

7. Madan R, Sawlani V, Gupta S, et al. MRI findings in Kallmann syndrome. Neurol India 2004:52:501-3.

8. Carstens MH. Development of the facial midlines. J Craniofac Surg 2002:13:129-87.

9. Hunter AG, Feldman W, Miller J. Characteristic craniofacial appearance and brachytelephalangy in a mother and son with Kallman syndrome in the son. Am J Med Genet 1986;24:527-32

10. dela Pena N. Kallmann's syndrome in two brothers. Philippine J Intern Med 1992; 30:25-34.

11. Abujbara MA, Hamamy HA, Jarrah NS, et al. Clinical and inheritance profiles of Kallmann syndrome in Jordan. Reprod Health 2004;1:5.

12. Chakraborty PP, Chowdhury SR, Mandal SK, et al. Doubtful descent, dilemma and diagnosis: a case of Kallmann syndrome. Singapore Med J 2007:48:259-62.

This pdf has been created automatically from the final edited text and images.

Copyright 2011 BMJ Publishing Group. All rights reserved. For permission to reuse any of this content visit http://group.bmj.com/group/rights-licensing/permissions.

BMJ Case Report Fellows may re-use this article for personal use and teaching without any further permission.

Please cite this article as follows (you will need to access the article online to obtain the date of publication).

Arkoncel MLCR, Arkoncel FRP, Lantion-Ang FL. A case of Kallmann syndrome. BMJ Case Reports 2011;10.1136/bcr.01.2011.3727, date of publication

Become a Fellow of BMJ Case Reports today and you can:

- Submit as many cases as you like

- Enjoy fast sympathetic peer review and rapid publication of accepted articles

- Access all the published articles

- Re-use any of the published material for personal use and teaching without further permission

For information on Institutional Fellowships contact consortiasales@bmjgroup.com

Visit casereports.bmj.com for more articles like this and to become a Fellow 